\title{
CREATING A VIRTUAL STUDY ABROAD EXPERIENCE TO RUSSIA
}

\author{
Jay Woodward ${ }^{1}$, \& Michelle Kwok ${ }^{2}$ \\ ${ }^{1}$ Department of Educational Psychology, Texas A\&M University (United States of America) \\ ${ }^{2}$ Department of Teaching, Learning and Culture, Texas A\&M University (United States of America)
}

\begin{abstract}
COVID-19 has drastically altered our world. Though travel is halted, global education does not have to stop. We used this time to reconceive the notion of study abroad and designed a study abroad program that could be facilitated virtually and enhanced with face-to-face classroom interaction. We were inspired to embark on this journey for several reasons. First, the realities of the pandemic create risks associated with international travel. Second, international experiences need to be more accessible-more students should be able to participate in global education, even if they do not have the means or ability to do so. We present our design considerations in building and implementing this virtual study abroad program. As part of the design, we partnered with VEXA (Virtual Experiences Abroad), a Moscow-based company that built the online interface and facilitated the interactions between our students and Russian citizens, including visits to a Russian Orthodox Church, the Bolshoi Ballet theater, and elementary and middle schools. We also brought elements of Russian culture to life through face-to-face experiences including a live cooking session with a Russian chef, discussions with a Russian Orthodox priest, and a ballet lesson with a company member of the Bolshoi theatre. These types of experiences facilitated group discussions and social interaction opportunities, crucial for establishing relationships. Overall, our main goal was to reconceive the traditional notion of study abroad while garnering results that would match the transformational gains that global education provides.
\end{abstract}

Keywords: Study abroad, technology, multicultural education, global education.

\section{Introduction}

Although COVID-19 has restricted travel, it has also by necessity inspired imagination and the adoption of new strategies and technologies to think beyond what is implausible and conceive what is possible about study abroad programs. Although borders are closed, global education initiatives do not have to cease. Furthermore, as the internet is quickly changing how we communicate with one another, the concept of "travel" needs to be re-examined. Sensing a gap, the authors used this time to reconceive the notion of study abroad and generated an international program that could be facilitated virtually and enhanced with face-to-face classroom interaction.

A semester-long virtual study abroad course was developed that sought to expand the boundaries of global education while reaching students who wouldn't otherwise be afforded the opportunity to travel. This course, which was initially offered in the Spring of 2021, was produced in partnership with VEXA, Virtual Experiences Abroad, a Moscow-based company that provided the interface and facilitated the interactions between students and Russian citizens. A number of modules and live experiences were created for the virtual study abroad; including 1) language and communication; 2) people and practices; 3) societal institutions; and 4) culture and the arts.

\section{Literature}

In a review of literature analyzing how universities across the world prepare their graduates for entrance into the 21st century workplace, Briguglio (2010) states that "although the number and variety of graduate attributes developed by universities may differ, the theme of preparing students for operating in global scenarios is seen repeatedly in higher education literature, with competencies in intercultural communication a priority" (p. 10, emphasis added). But how are these competencies structured or achieved? The conventional means of programming is through a standard study abroad experience (Anderson \& Lawton, 2015). In study abroad programs, students are situated in an unfamiliar culture that compels them to pay close attention to and rapidly develop strategies to communicate ideas across 
cultures as well as formulate a perspective of their own culture. According to the "Open Doors" report issued by The Institute of International Education (2020), in a typical year, U.S. institutions send nearly 350,000 students abroad. However, the reality is that the pandemic has restricted movement, and halted international travel. Global engagement, in its most traditional form, has been grounded.

The expansion of both the domains and audiences of a traditional study abroad experience is at the heart of this course design. First, international experiences need to be more accessible - more students should be able to participate in global education, even if they do not have the means or ability to do so (Whatley \& Raby, 2020). In a recent article released by The Chronicle of Higher Education, it was reported that just $2 \%$ of undergraduates study abroad; a small percentage of the overall college population (Fisher, 2021). But diving into the breakdown of that number further reveals a disparaging and discouraging pattern. The International Coalition for Global Education and Exchange (Artis et al., 2021) reports that racial or ethnic minority students represent less than one-third of study abroad participants even though their proportional representation in the U.S. college population approaches one-half.

Compounding this further is that the "cost of participating in study abroad programs can be a serious impediment for many students" despite a clear desire to study abroad (Amani \& Kim, 2018, p. 680). Findings by Stroud (2010) reinforce this notion further by indicating that aside from cost, fear of discrimination was also a salient influential factor as well. Deterrents and barriers to participation not only pertain to ethnic and racial minority students, but also non-traditional students as well. Another factor could be family obligations and responsibilities, with students who are employed having to endure financial hardships to take time off, and no guarantee they will have a job when they return (Amani \& Kim, 2018, p. 680). Therefore, our course design is based in equity, in that it will allow students, for whom study abroad might not have been a possibility, the chance to experience the transformational learning that these opportunities provide.

\section{Course design}

The course itself was initially designed with intercultural communication as a key focus. The course began on the topic of communication; starting with the Russian language itself. Students learned the Cyrillic alphabet, and quickly applied their knowledge to introduce themselves and hold short conversations with Russian language teachers. From the module on language, students were taken through cross-cultural experiences across a variety of societal institutions. For example, students explored the Russian Orthodox Church, where they were able to draw distinctions between their own theological perspectives and predominant perspectives in Russia, accentuated through interviews with Russian Orthodox clergy and viewing of artifacts used in worship. Students were led on a private tour of the Faberge Museum, learning about the history of Faberge as well as traditional costume of that time. Students also engaged in cultural exchanges with elementary and high school-aged children in which they shared about daily life and traditions across the US and Russia.

We also brought elements of Russian culture to life through experiences that allowed for collaboration and enhanced a sense of community in our group (Ritz, 2011). These included engaging in a live cooking session with a five-star Russian chef to make a traditional meal. Students were also challenged to learn ballet from a Russian ballerina and hear about her training regime. From there, students gained a behind-the-scenes look into the Bolshoi Ballet, where students were able to see snippets of rehearsals and converse with company members.

\section{Methods of assessment}

The main measurement tool built into this course provides quantitative and qualitative data to show how students have grown as a result of participating in this virtual abroad experience. Students took two norm-based assessments pre- and post-course: 1) the Global Perspectives Inventory (GPI), and 2) an Intercultural Development Inventory (IDI). The GPI measures cognitive, interpersonal, and intrapersonal gains as a result of studying abroad. Students were classified on subscales related to 1) Knowing; 2) Knowledge, 3) Identity, 4) Affect, 5) Social Responsibility, and 6) Social Interactions. A t-test for mean differences will determine if students demonstrate significant change on any of these aspects as a result of participation. The first iteration of this course is currently being completed, so we do not yet have data to reflect pre-post changes.

The second instrument, the IDI, assesses intercultural competence. Student answers to the IDI will give them quantitative data as to their perceived orientation (PO) towards other cultures (where they think they are) along with their developmental orientation (DO) towards other cultures (where the instrument assesses them to be) and the resulting developmental gap. The continuum that the IDI rates students on is a 5-point continuum that ranges from Denial (limited capability for understanding and responding to cultural difference) all the way to Adaptation (shifting one's own cultural perspective and changing behavior in culturally appropriate ways). Data from the IDI shows that only $3 \%$ of individuals 
fall into the Denial category and only $2 \%$ will ever achieve Adaptation. The majority of individuals fall in the middle, and a goal of this virtual study abroad is to engage students in "needle moving" experiences.

When students complete the IDI, their results are presented to them in a debriefing session to provide them key insights into how they make sense of cultural differences. They are then presented with a series of choices and options to systematically increase their intercultural competence and close the gap between their (DO) and (PO) by working through a customized Intercultural Development Plan (IDP). The IDP is tied directly to the results from the IDI and is set up to allow students to gain insights concerning identified intercultural challenges they might be facing and identify personal intercultural competence development goals that are important for them to progress through during the semester.

\section{Preliminary findings}

Although we do not have pre-post data to report, individual student reflections do reveal the impact of this virtual study abroad course. Student reflections reveal how powerful the live interactions were. In of the live experiences, we rented a local restaurant and live-streamed in a Russian chef to teach us traditional dishes. The owner and chef of the local restaurant also supported us during the lesson. This experience made a strong impact on one of our students, who recalls:

FANTASTIC experience and nothing less. I have never experienced something like this in my college career that went so in depth and beyond a picture on a slide show. I will remember this experience until I can't remember anything anymore! Honestly, when I look back on college I KNOW this will be one of the first things to come to mind every time. Why? We don't get experiences like this normally, so I am SO appreciative that we had this opportunity. It was engaging, it was immersive, it was awesome to learn directly from a professional Chef who was courteous enough to spend the time teaching us! When I signed up for the study abroad, honestly, this was the type of experience I was hoping for!

Live experiences such as this one helped students feel immersed in a different culture, without ever having to leave town.

Another student foregrounds the importance of personal reflection on their growth. In the following, the student reflects on being encouraged to engage in cultural activities outside of class time.

Seeking out unique and challenging activities to spur my development was really great, especially outside the classroom environment. However, taking the time to really reflect on what I participated in, examine the impact it left on me, and how I can take that moving forward was something I was truly appreciative of.

In addition to building interactive virtual and live experiences, we made sure to provide consistent avenues for students to engage in self-reflection as well as reflecting on their role(s) in the different spaces and cultures they participate in. It is through the purposeful programming of these activities and assessments that we aim to demonstrate participant growth and the achievement of positive learning outcomes in future semesters. Moving forward, our plan is to deepen course content and enrich live experiences to promote further intercultural awareness and communication.

\section{References}

Amani, M., \& Kim, M. M. (2018). Study abroad participation at community colleges: Students' decision and influential factors. Community College Journal of Research and Practice, 42(10), 678-692.

Anderson, P. H., \& Lawton, L. (2015). Student motivation to study abroad and their intercultural development. Frontiers: The Interdisciplinary Journal of Study Abroad.

Artis, R. C., Book, C. L., Clinton, J., Lucas, J. S., Pellow, J. P., \& Whitehead, D. M. (2021). Advancing Global Stability and U.S. National Security through Peaceful Exchange. Retrieved from https://static1.squarespace.com/static/5e947e0237a0b6041f0cd80a/t/6064b5b69341cc22bb8a8c08/ 1617212872956/TIC-WhitePaper_3-21_web.pdf

Briguglio, C. (2007). Educating the business graduate of the 21st century: Communication for a globalized world. International Journal of Teaching and Learning in Higher Education, 19(1), 8-20.

Fisher, K. (2021, April 1). The year without study abroad. Retrieved from https://www.chronicle.com/article/the-year-without-study-abroad?cid=gen_sign_in

Ritz, A. A. (2011). The educational value of short-term study abroad programs as course components. Journal of Teaching in Travel \& Tourism, 11(2), 164-178.

The Institute of International Education (IIE). (2020). Open doors report. New York, NY.

Whatley, M., \& Raby, R. L. (2020). Understanding Inclusion and Equity in Community College Education Abroad. Frontiers: The Interdisciplinary Journal of Study Abroad, 32(1), 80-103. 